\title{
Serum placental growth factor in late first trimester of pregnancy for prediction of preeclampsia in primigravida - a case control study
}

\author{
Rachna Agarwal $^{1 *}$, Shweta Chaudhary ${ }^{1}$, Rajarshi Kar ${ }^{2}$, Gita Radhakrishnan ${ }^{1}$, Richa Sharma ${ }^{1}$ \\ ${ }^{1}$ Department of Obstetrics and Gynaecology, University College of Medical Sciences and Guru Teg Bahadur, Delhi \\ 110095, India \\ ${ }^{2}$ Department of Biochemistry, University College of Medical Sciences and Guru Teg Bahadur, Delhi 110095, India
}

Received: 17 October 2016

Accepted: 29 November 2016

\section{*Correspondence:}

Dr. Rachna Agarwal,

E-mail: rachna_anila@yahoo.co.in

Copyright: () the author(s), publisher and licensee Medip Academy. This is an open-access article distributed under the terms of the Creative Commons Attribution Non-Commercial License, which permits unrestricted non-commercial use, distribution, and reproduction in any medium, provided the original work is properly cited.

\begin{abstract}
Background: We studied the correlation of serum PLGF levels at 11-14 weeks in primigravida for prediction of future preeclampsia in a prospective nested case control study and estimated the critical levels of PLGF for possible use as screening test.

Methods: Subjects with preeclampsia/gestational hypertension were taken as cases with an equal number of controls. Results: Out of 300 participants, final analysis was possible in 291 subjects. Thirty five were cases; two had early PE, 15 late PE and 18 had GH. PLGF level was lower in cases $(20 \mathrm{pg} / \mathrm{ml})$ compared to controls (79 pg/ml). PLGF was significantly lower in PE cases $(15 \mathrm{pg} / \mathrm{ml})$ compared to $\mathrm{GH}$ cases $(34 \mathrm{pg} / \mathrm{ml})$. PLGF had maximum area under the ROC curve (AUC) for PE with value of 0.867. Further, late PE had more AUC (0.853) as compared to GH (0.759). The cut off value for prediction of PE was found to be $<30 \mathrm{pg} / \mathrm{ml}$ with $88.2 \%$ sensitivity and $71.4 \%$ specificity.

Conclusions: PLGF levels were significantly lower in first trimester serum samples of subjects who later developed either preeclampsia or gestational hypertension. PLGF had better detection rate for PE and late PE as compared to $\mathrm{GH}$.
\end{abstract}

Keywords: Gestational hypertension, PGLF, Preeclampsia

\section{INTRODUCTION}

Preeclampsia (PE) incidence varies from 5-15\% worldwide, making this condition one of the most common complication of pregnancy. $\mathrm{PE}$ is responsible for about $18 \%$ of maternal deaths and up to $40 \%$ of fetal mortality. Recent guidelines by NICE recommend routine screening in first trimester for specific risk factors for preeclampsia and early treatment to reduce risk of preeclampsia. ${ }^{1}$ Thus, there is a growing need to formulate first trimester screening model for preeclampsia for timely intervention.

Several western studies have shown the role of circulating growth factors in pathogenesis of PE. ${ }^{2-4}$ Different biochemical markers like Placental protein 13 (PP-13), soluble FMS like tyrosine kinase (sFlt-1), soluble endoglin (s-Eng) and placental growth factor (PLGF) have been investigated based on pathophysiology of PE such as placental dysfunction, release of cytokines, activation of coagulation cascade and endothelial dysfunction. $^{2-4}$ Evidence supports that altered levels of these becomes apparent from first trimester of pregnancy in future pre-eclamptic patients. Of these, placental growth factor (PLGF), a small hematological molecule, is one of the most promising. However, the role of PLGF as a screening tool in preeclampsia is still not established, especially in primigravida. ${ }^{3-6}$

Our aim was to study the correlation of serum PLGF levels at 11-14 weeks in primigravida for prediction of future preeclampsia and gestation hypertension and to estimate the critical levels of PLGF for possible use as screening test. 


\section{METHODS}

The present study (2013-15) was a prospective nested case control study for hypertensive disorders in primigravida ( $<40$ years) attending their first hospital visit with singleton pregnancy at 11-14 weeks of gestation in a tertiary care health care setting in a low income country. Written informed consent was obtained from the participating women and ethical approval was obtained from Institutional Ethical Committee. The exclusion criteria were women with known smoking history, chronic hypertension, diabetes or gestational diabetes. Pregnancies complicated with anomalous fetus, $\mathrm{Rh}$ isoimmunisation, thyroid dysfunction or collagen, liver or kidney diseases were also excluded. The Table 1 depicts the flow methodology of the study.

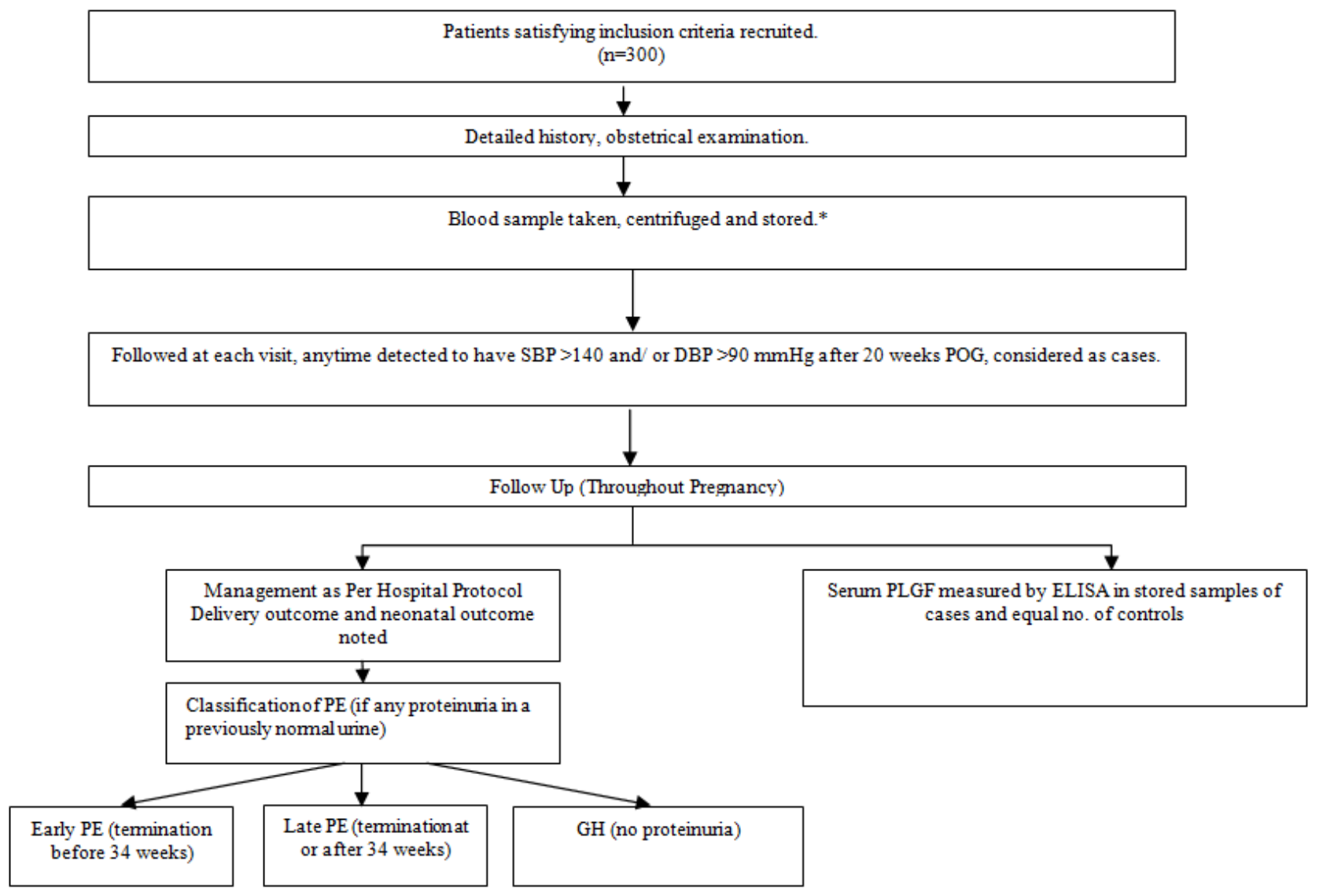

*2 $\mathrm{ml}$ of blood sample was taken in plain vial. Blood sample was centrifuged at $3000 \mathrm{rpm}$ for 15 minutes and separated serum was stored in $1 \mathrm{ml}$ aliquots at $-70{ }^{\circ} \mathrm{C}$ for later analysis of PLGF in cases and controls.

\section{Figure 1: Methodology of the study.}

Out of 300 participants, five subjects had spontaneous abortion between 20 to 27 weeks period of gestation. Further, four subjects were loss to follow up. Thus, final analysis was possible in 291 subjects. Thirty five subjects had Preeclampsia (PE)/Gestational hypertension (GH) and were taken as cases and an equal number of normotensive non-proteinuric subjects were taken as controls. PLGF levels were assessed in stored serum samples of cases and controls $(n=70)$.

The PLGF level was estimated from stored serum samples of cases and controls by ELISA based kit. Using the standard technique, the absorbance values for standard, case and control serum sample was noted. Using the mean absorbance value [in picograms per millilitre $(\mathrm{pg} / \mathrm{ml})]$ for each sample, its corresponding concentration was calculated from this standard curve.

\section{Statistical analysis}

Statistical software SPSS (version 20.0) was used for statistical analysis. Non- parametric parameters were compared by Kruskal-Wallis test. ROC curve were plotted for PLGF levels using univariate analysis. Detection rates were calculated by ROC curve for $5 \%$ and $10 \%$ false positive rates (FPR).

\section{RESULTS}

The mean age of study population $(n=291)$ was $22.6 \pm 2.4$ years (range, 18-34 years). In our study, there were total of $12.03 \%(n=35)$ cases of preeclampsia and gestational hypertension. Among these, 5.8\% $(\mathrm{n}=17)$ had preeclampsia (PE) and 6.2\% $(\mathrm{n}=18)$ subjects had gestational hypertension $(\mathrm{GH})$. 
Table 1: Comparison of median PLGF levels between cases and controls.

\begin{tabular}{|lll|}
\hline Outcome group & $\begin{array}{l}\text { PLGF }(\mathrm{pg} / \mathrm{ml}) \\
\text { median }(\mathrm{IQR})\end{array}$ & $\begin{array}{l}\text { p value* } \\
\text { when } \\
\text { compared } \\
\text { to } \\
\text { controls }\end{array}$ \\
\hline Controls $(\mathrm{n}=35)$ & $\begin{array}{l}79.0(28.0- \\
116.0)\end{array}$ \\
\hline Cases & $20.0(14.0-38.0)$ & 0.000 \\
\hline All $(\mathrm{n}=35)$ & $15.0(11.0-22.5)$ & 0.000 \\
\hline $\begin{array}{l}\text { Preeclampsia } \\
(\mathrm{n}=17)\end{array}$ & $34.0(15.7-45.0)$ & 0.002 \\
\hline $\begin{array}{l}\text { Gestational } \\
\text { Hypertension } \\
(\mathrm{n}=18)\end{array}$ & \\
\hline *p value $<0.05$ was considered significant, Kruskal-Wallis test.
\end{tabular}

The median PLGF levels in all cases $(n=35), \operatorname{PE~}(n=17)$, $\mathrm{GH}(\mathrm{n}=18)$ was statistically significant when compared to controls (Table 2). Between cases, the median PLGF level in PE was 15 (11.0-22.5) pg/ml compared to $\mathrm{GH}$ with the levels as $34(15.7-45.0) \mathrm{pg} / \mathrm{ml}$. This difference reached significance with $\mathrm{p}=0.008$.

Out of total 17 cases of preeclampsia, patients with early preeclampsia $(\mathrm{n}=2$; median PLGF levels $11.0 \mathrm{pg} / \mathrm{ml}$ delivery) had lower PLGF levels compared to late preeclampsia ( $\mathrm{n}=15$; median PLGF levels $22.0 \mathrm{pg} / \mathrm{ml}$ ). This difference could not reach statistical significance. The PLGF levels in cases with PE, late PE and GH were plotted on receiver operating characteristic (ROC) curve using univariate analysis (Table 3 ). This analysis was not possible in early PE due to two cases. PLGF had maximum area under the ROC curve (AUC) for PE with value of 0.867. Further, late PE had more AUC (0.853) as compared to GH (0.759). PLGF had better detection rate for PE and late PE as compared to GH. The cut off value for prediction of PE was found to be $<30 \mathrm{pg} / \mathrm{ml}$ with $88.2 \%$ sensitivity and $71.4 \%$ specificity derived from ROC curve. The cut off value for prediction of late PE was $<32 \mathrm{pg} / \mathrm{ml}$ with sensitivity of $86.7 \%$ and specificity of $74.3 \%$. The cut off value for prediction of GH was $<50$ $\mathrm{pg} / \mathrm{ml}$ with sensitivity of $88.9 \%$ and specificity of $65.7 \%$.

Table 3: Comparison of performance of screening for PE, late PE and GH by AUC and detection rate for PLGF.

\begin{tabular}{|llll|}
\hline PLGF & Preeclampsia & Late preeclampsia & Gestational hypertension \\
\hline $\begin{array}{l}\text { Area under ROC curve } \\
(95 \% \text { CI) }\end{array}$ & $0.867(0.771-0.964)$ & $0.853(0.749-0.957)$ & $0.759(0.632-0.886)$ \\
\hline Detection Rate (5\% FPR) & $40 \%$ & $40 \%$ & $16 \%$ \\
\hline Detection Rate (10\% FPR) & $51 \%$ & $46 \%$ & $21 \%$ \\
\hline
\end{tabular}

\section{DISCUSSION}

The availability of an effective screening tool for PE could have direct impact on the medical management of pregnant women and their child but also on health costs associated with this medical condition. PLGF as a marker has shown some promise in this regard but supporting studies in favour especially from low income countries where burden is most felt, are few. Parra-Cordero et al has even compared PLGF with other biochemical markers like s-Flt-1 and s-Eng level and concluded that PLGF as best biochemical marker for prediction of PE. ${ }^{7}$ Previous studies were done in general population with recognised risk factors such as pre-existing medical conditions and history of preeclampsia. ${ }^{6,7}$ Our prospective study targeted low-risk nulliparous women where incidence of PE is greater.

\section{Performance of PLGF (Biochemical marker)}

The finding of median PLGF levels being significantly lower in cases $(\mathrm{PE} / \mathrm{GH})(20 \mathrm{pg} / \mathrm{ml})$ compared to controls $(79 \mathrm{pg} / \mathrm{ml})$ was replicated in our study. ${ }^{2,3,6-8}$ Furthermore, PLGF was much lower in cases with PE (15 pg/ml) as compared to cases with GH (34 pg/ml). Study by Schneuer et al also found median PLGF level in all PE cases and late PE cases significantly lower as compared to unaffected controls with median values as $21.3,20.7$ and $24.1 \mathrm{pg} / \mathrm{ml}$ respectively. ${ }^{6}$ In another study by Lai et al, median PLGF level in all PE cases and late PE cases was significantly lower compared to controls with PLGF level as 25.1, 27.2 and $34.7 \mathrm{pg} / \mathrm{ml}$ respectively. ${ }^{2}$ The Poon et al study with base-cohort population of 7797 singleton pregnancies, including 34 case subjects also had similar findings. ${ }^{8}$ They inferred that median PLGF level was significantly lower in late PE cases and GH cases compared to unaffected controls with median values as 29.8, 29.2 and $33.7 \mathrm{pg} / \mathrm{ml}$ respectively. Our median PLGF level in late PE cases $(22.0 \mathrm{pg} / \mathrm{ml})$ was also comparable to several other reports $\left\{(27.2 \mathrm{pg} / \mathrm{ml})^{2},(29.8\right.$ $\mathrm{pg} / \mathrm{ml})^{8}$ and $\left.(20.7 \mathrm{pg} / \mathrm{ml})^{6}\right\}$.

Our study had only two cases of early PE with mean PLGF level as $11.3 \mathrm{pg} / \mathrm{ml}$. Hence early PE was not compared statistically with GH cases and controls in our study. However in literature PLGF has been ascertained to be lower in early PE versus controls. ${ }^{5,9}$ Being a prospective study, our study showed association between 
lower PLGF levels in first trimester to development of preeclampsia and gestational hypertension.

\section{PLGF as a screening tool}

The PLGF levels in cases when plotted on (ROC) curve had more area for PE (0.867) and late PE (0.853) as compared to GH (0.759) thereby suggesting that PLGF assessment had better detection rate for $\mathrm{PE}$ and late $\mathrm{PE}$. Study by Myatt et al had AUC of 0.61 (0.56-0.66) for preeclampsia cases. ${ }^{3}$ Various other studies comparing the role of PLGF versus other biochemical markers have been done using AUC. ${ }^{2,10}$ In these studies PLGF has emerged as of best predictive value with maximum AUC for prediction of $\mathrm{PE}^{2}$ In one of the pioneer studies involving large number $(n=5,099)$ of pregnant females where 145 developed PE (2.84\%), Lai et al found AUC of 0.734 for late PE cases. ${ }^{2}$ Similarly, Youssef et al found that for PLGF, AUC was 0.703 (0.502-0.904) for late PE cases. $^{10}$

PLGF has better detection rate for PE and late PE. ${ }^{2,10}$ In present study, PLGF had detection rate 51\%, 46\%, 21\% with $10 \%$ FPR for PE, late PE and GH respectively. Same conclusion was drawn by Lai et al where detection rate for late PE was $44.4 \%$ for $10 \% \mathrm{FPR}^{2}$ Youssef et al found an even higher detection rate with PLGF of $61.5 \%$ for $10 \%$ FPR for late PE cases. ${ }^{10}$

The study by Ghosh et al has calculated a cut-off value for PLGF $(<144 \mathrm{pg} / \mathrm{ml})$ as predictor of early onset preeclampsia in obese/overweight women at 20-22 weeks of gestation. ${ }^{11}$.Our study although not comparable to above study gave lower threshold for cases. The cut off value of PLGF for prediction of PE was found to be $<30$ $\mathrm{pg} / \mathrm{ml}$ with $8.2 \%$ sensitivity and $71.4 \%$ specificity by ROC curve. The PLGF cut off level for prediction of late PE was derived to be $<32 \mathrm{pg} / \mathrm{ml}$ with sensitivity of $86.7 \%$ and specificity of $74.3 \%$. Further, the cut off level of PLGF for prediction of $\mathrm{GH}$ was $<50 \mathrm{pg} / \mathrm{ml}$ with sensitivity of $88.9 \%$ and specificity of $65.7 \%$. Thus, it was derived that PLGF level of less than $50 \mathrm{pg} / \mathrm{ml}$ can predict future development of $\mathrm{GH}$ and if this level is further less than $30 \mathrm{pg} / \mathrm{ml}$ it can possibly lead to future $\mathrm{PE}$ in low risk nulliparous women.

For a screening tool to be of value, it should be cost effective, safe to use, accurate and validated. Except for cost-factor, first trimester PLGF seems to have the potential for early prediction of PE. It is also acceptable tool as timing of sampling is first trimester which coincides with sampling for routine antenatal investigations and other screening protocols. Additionally, PLGF has a good balance between sensitivity and specificity.

Our study has certain limitations which we like to acknowledge. PLGF values were not available in multiples of expected median (MoM). ${ }^{5,7}$ This calculation of MoM for total study population was not possible in our study due to financial constraints. The current study was limited by relatively small number of affected women $(n=35)$ including early PE $(n=2)$, thus reducing the power of the study to analyse the predictive accuracy of this marker. Despite these limitations, our study contributes further information for establishing reference ranges and cut off values while using PLGF as a screening tool for PE.

We therefore recommend further larger multicentric studies for validation of PLGF and evaluation of its role as ideal screening tool for preeclampsia. Its diagnostic accuracy and cut off values need further refinement.

\section{CONCLUSION}

PLGF had good detection rate for preeclampsia as compared to $\mathrm{GH}$. It has potential screening value for detection of preeclampsia in nulliparous women in our clinical setting. PLGF levels were significantly lower in first trimester serum samples of subjects who later developed PE.

\section{Funding: No funding sources}

Conflict of interest: None declared

Ethical approval: The study was approved by the Institutional Ethics Committee

\section{REFERENCES}

1. American College of Obstetricians and Gynecologists. Hypertension in Pregnancy. Report of the American College of Obstetricians and Gynecologists' Task Force on Hypertension in Pregnancy. Obstet Gynecol. 2013;122:1122-31.

2. Lai J, Pinas A, Poon LC, Agathokleous M, Nicolaides KH. Maternal serum placental growth factor, pregnancy-associated plasma protein-a and free $\beta$-human chorionic gonadotrophin at 30-33 weeks in the prediction of preeclampsia. Fetal Diagn Ther. 2013;33:164-72.

3. Myatt L, Clifton RG, Roberts JM, Spong CY, Hauth JC, Varner MW, et al. First-trimester prediction of preeclampsia in nulliparous women at low risk. Obstet Gynecol. 2012; 119:1234-42.

4. Myers JE, Kenny LC, McCowan LM, Chan EH, Dekker GA, Poston L, et al: Angiogenic factors combined with clinical risk factors to predict preterm preeclampsia in nulliparous women: a predictive test accuracy study. Br J Obstet Gynaecol. 2013;120:1215-3.

5. Parra-Cordero M, Rodrigo R, Barja P, Bosco C, Rencoret G, Sepúlveda-Martinez A, et al. Prediction of early and late preeclampsia from maternal characteristics, uterine artery Doppler and markers of vasculogenesis during first trimester of pregnancy. Ultrasound Obstet Gynecol. 2013;41:538-44.

6. Schneuer FJ, Nassar N, Guilbert C, Tasevski V, Ashton AW, Morris JM, et al. First trimester screening of serum soluble fms-like tyrosine kinase-1 
and placental growth factor predicting hypertensive disorders of pregnancy. Pregnancy Hypertens. 2013;3:215-21.

7. Akolekar R, Syngelaki A, Sarquis R, Zvanca M, Nicolaides KH. Prediction of early, intermediate and late preeclampsia from maternal factors, biophysical and biochemical markers at 11-13 weeks. Prenat Diagn. 2011;31:66-74.

8. Poon LC, Kametas NA, Maiz N, Akolekar R, Nicolaides KH. First-trimester prediction of hypertensive disorders in pregnancy. Hypertension. 2009;53:812-8.

9. Noori M, Donald AE, Angelakopoulou A, Hingorani AD, Williams DJ. Prospective study of placental angiogenic factors and maternal vascular function before and after preeclampsia and gestational hypertension. Circulation. 2010;122:478-87.

10. Youssef A, Righetti F, Morano D, Rizzo N, Farina A. Uterine artery Doppler and biochemical markers (PAPP-A, PIGF, sFlt-1, P-selectin, NGAL) at $11+0$ to $13+6$ weeks in the prediction of late $(>34$ weeks) preeclampsia. Prenat Diagn. 2011;31:1141-6.

11. Ghosh SK, Raheja S, Tuli A, Raghunandan C, Agarwal S. Serum placental growth factor as a predictor of early onset preeclampsia in overweight/obese pregnant women. J Am Soc Hypertens. 2013;7:137-48.

Cite this article as: Agarwal R, Chaudhary S, Kar R, Radhakrishnan G, Sharma R. Serum placental growth factor in late first trimester of pregnancy for prediction of preeclampsia in primigravida - a case control study. Int J Reprod Contracept Obstet Gynecol 2017;6:106-10. 